LITERATURA E OUTRAS LINGUAGENS 


\title{
ALGUMAS CANÇÕES EM CURITIBA
}

\author{
Marcelo Sandmann ${ }^{*}$
}



om aquela mescla típica de fina agudeza e desbragada provocação que caracterizaram sempre as suas intervenções, Paulo Leminski talvez tenha sido feliz ao tentar dar conta, de modo polêmico e conciso, das razões da relativa insignificância de Curitiba no cenário cultural do país. Precisamente em dois ensaios do seu Anseios cripticos" - "Sem sexo, neca de criação" e "Culturitiba" - , a questão é apresentada e rapidamente resolvida.

Algumas das suas formulações são instigantes, Leminski tornou-se figura bastante emblemática e de visibilidade invejável para além dos limites da cidade - portanto, pode-se vislumbrar ai um bom ponto de partida para este artigo sobre a recente cena musical curitibana.

O problema que se põe de imediato é o da ausência de uma contribuição mais consistente da cidade na arte e na cultura do país. Segundo o poeta, Curitiba parece não devolver na mesma proporção aquilo tudo que consome. As razões sociais e econômicas poderiam ser buscadas ali adiante - no imigrante. Mais

* Universidade Federal do Paraná.

I LEMINSKI, Paulo. Anseios Cripticos. Curitiba: Criar. 1986 
explicitamente: na impregnação, na alma local, de um certo tipo de comportamento e mentalidade que se enraizou aqui com a imigração européia.

Para Leminski, é característica do imigrante a "mística do trabalho", dentro de moldes bastante puritanos, à qual se associa ainda uma complementar "mística da poupança", responsáveis as duas pela repressão de tudo aquilo que se afigura demasiadamente gratuito. $\mathrm{O}$ trabalho e a poupança não deixam espaço para o lazer e o usufruto. Reprime-se o sexo não orientado para a procriação, reprime-se o criativo, reprime-se o lúdico. $\mathrm{E}$ a arte acaba sendo tragada de roldão.

Vale a pena, pelo seu sabor, transcrever algumas passagens da prosa do poeta: "Freudianamente, Curitiba é a retenção das fezes. Nosso pecado é a avareza. Ora, criar é esbanjar. Só por excessos se cria. Por uma exuberância." E logo a seguir: "Ora, para a mística imigrante do trabalho e da poupança, toda exuberância é prodigalidade, insensatez, erro. Em cultura, Curitiba não emite sinais fortes, sinais transformadores, extremos, extremismos, exageros. Curitiba guarda-se."

Vinculadamente a essas formulações, permeia toda a reflexão de Leminski a idéia de que Curitiba é uma cidade classe-média em demasia. $E$ isso, bem ao contrário do que se poderia esperar, parece não contribuir para a necessária fermentação cultural. "Uma infra-estrutura propícia não gera, automaticamente, superestrutura rica e produtiva." Curitiba, segundo o poeta. "desmente o determinismo econômico." $\mathrm{O}$ bem-estar, a relativa riqueza, o acesso à escola, o acesso aos bens culturais que vêm de fora não encontram uma contrapartida significativamente criativa. A classe-média se compraz com o mero consumo. E Leminski é irônico a esse respeito: "O acesso aos bens de civilização industriais, a grande aventura existencial da classe-média". Faltanos, na perspectiva polêmica do poeta, justamente a falta, a carência, a fome: "Talvez só se produza, culturalmente, em resposta a uma grande carência." 4

Seguindo por essa linha de reflexão, fica-se então a um passo desta outra constatação, aliás das mais instigantes: "Faz muita falta em Curitiba o húmus popular, o substrato de formas demóticas, por baixo, fertilizando, estimulando, provocando. Curitiba não tem folclore. Não há manifestações artisticas populares autônomas, de base." Sem essa raiz popular, a cidade - capitaneada pela sua classe-média - parece não se encontrar apta a gerar uma cultura própria que

2 LEMINSKI. op.cit.p. 78

3 Ibid. p. 113

4 Ibid. p.114

s Ibid. p. 80 
se coloque à altura de outros grandes centros brasileiros. " $\grave{A}$ classe média, falta verticalidade. Profundidade no tempo. Raízes."6 fazer?",

E a proposição final é bastante precisa: "Sem raízes e sem carência, que

Se as reflexões de Leminski têm de fato alguma validade para além da polêmica, talvez seja muito mais pelo diagnóstico que se faz ai de toda uma situação - que é ainda em certa medida a da cidade - e por alguns insights explicativos bastante felizes, do que pela consistência e rigor sociológicos de todas as explicações propostas. Publicados em livro em 1986 (mas de redação e primeira publicação provavelmente anteriores), dez anos depois estes ensaios não foram de todo desmentidos.

Centrando o foco da atenção sobre a música popular, que é o que nos interessa aqui mais de perto, certamente a constatação da ausência de um "húmus popular" fertilizando o solo da criação é uma proposição de peso. Sem esse solo fértil, não há consistência nem profundidade de raiz. E a música popular, por definição, precisa de um forte enraizamento popular.

Mas se o solo fértil social praticamente inexiste, Curitiba apesar disso parece estar querendo ultimamente ensaiar a mudança. $E$ ao invés de fixar raizes num terreno propício inexistente, a cidade inverte o vetor do enraizamento, para fixar as suas raízes no ar. $E$ as raizes são agora antenas, absorvendo o húmus fértil que o pais e o mundo nos oferecem (sempre nos ofereceram). Se vamos saber processar devidamente $o$ alimento, e com ele suprir a carência finalmente insinuada, é questão que se deve deixar agora para o tempo.

O ano de 1995 marca certamente um instante de virada na cena musical curitibana. A música popular local, que vinha sobrevivendo basicamente (com raros instantes de exceção) de modestos shows pelos espaços habituais de espetáculo da cidade, praticamente apartada de um público mais significativo, e viva quase que somente no desejo afirmativo de seus artistas, começou a ganhar um novo espaço de presença e divulgação. Curitiba vem vivendo desde 0 ano passado um verdadeiro boom de gravações em estúdio e laçamentos em CD.

Quer seja se beneficiando da "Lei Municipal de Incentivos Fiscais à Cultura", ou desenvolvendo o seu projeto às próprias custas, ou ainda contando com a colaboração de alguns selos de maior ou menor expressão no mercado fonográfico do país, os músicos curitibanos parecem estar dispostos a mostrar que, neste momento, há alguma "fome" - para retornar à expressão de

7 Ibid. p.115 
Leminski -, há algum desejo de dissipar a "carência". A quantidade de material já lançado ou que está a caminho é bastante surpreendente para os padrões locais.

Em 18 de agosto de 1995, no suplemento "Folha Viva Curitiba", do jornal Folha de Londrina, divulgou-se uma lista de vários artistas (com seus respectivos estilos) com discos então já lançados ou com lançamento previsto para o final do ano ou inicios do ano de 1996. Em 28 de fevereiro de 1996, o "Caderno G", do jornal Gazeta do Povo, em reportagem intitulada "Made in Paraná", apresentou outra relação de lançamentos (com alguns nomes ausentes da matéria anterior), acompanhada de um breve comentário sobre os discos apresentados. Além dos nomes contidos nessas relações, há ainda alguns outros que podem ser citados. A simples listagem de todo esse material (Tabela 1) revela-se bastante eloqüente. ${ }^{8}$

Em todo o caso, enquanto o país demora a ser conquistado, a música curitibana vai procurando - na contramão dos interesses da maior parte das rádios e canais de televisão - conquistar um público local. E nesse desejo de se projetar em direção a um público seu, as canções acabam por fazer da própria cidade matéria a ser cantada. Curitiba vai se tornando, inevitavelmente, objeto de referência para várias das canções.

Selecionei três composições em que a cidade de Curitiba surge cantada, quer como tema principal, quer como pano de fundo para um outro tema. São elas um bom termômetro para o que subterraneamente parece estar se processando na cidadeA primeira delas é "Não dê pipoca ao turista", extraida do disco Os homens são todos iguais, de Carlos Careqa. Gravado entre 1991 e 1993. originalmente lançado em LP pelo selo paulista Camerati e relançado em CD em 1996 pelo selo Velas, Os homens são todos iguais conta com participações especialissimas de artistas de destaque na cena alternativa, como Arrigo Barnabé, Itamar Assumpção, Tetê Espindola e Cida Moreyra. "Não dê pipoca ao turista" (com letra de Carlos Careqa, Adriano Sátiro e Oswaldo Rios, e música de Carlos Careqa) traz a participação de Arrigo no piano e na voz ao lado do

8 "Folha viva Curitiba". 18/08/95. Suplemento semanal da. Folha de Londrina para Curitiba. BROWNE e SMITH. "Made in Paraná". In: Gazela do Povo. 28/02/96. Caderno "Cultura G".

Acrescentei às relaçòes dos suplementos alguns outros nomes de grupos e artistas fornecidos por lojas de discos da cidade. Deixei de lado os discos lançados em anos anteriores a 1995. bem como os de música instrumental e de música erudita. A caracterização do estilo dos artistas. apresentada aqui de forma simplificada, baseia-se na que consta dos citados suplementos. Tomei a liberdade de caracterizar os discos ausentes das relaçỏes desses periódicos a partir de uma simples audiçào dos mesmos.

Seria bom frisar que a listagem apresentada aqui neste artigo não pretende dar conta de toda a satra curitibana recente de música popular. mas sim simplesmente alicerçar a tese de que se vive neste instante uma grande efervescência em termos de produção de discos em Curitiba. Os limites da presente listagem são os limites das próprias fontes consultadas. 
próprio Careqa..

TABELA 1

\begin{tabular}{l|l|l} 
ARTISTA & DISCO & ESTILO \\
\hline Alexandre Nero & "Camaleão" & $\mathrm{mpb}$ \\
\hline * Amen Corner & "Jachol Ve Tehilá" & rock \\
\hline Aurora 21 & "Aurora 2l" & rock \\
\hline Bartenders & - & rock/blues \\
\hline * Beijo AA Força & "Sem Suingue" & rock/mpb \\
\hline Boi Mamão & "Boi Mamão" & rock/mpb \\
\hline * Boi Mamão, Resist Con- & "Alface" (coletânea) & rock \\
\hline * Carlos Careqa & & \\
\hline *Fato & $\begin{array}{l}\text { "Os homens são todos Iguais" } \\
\text { (relanç. CD) }\end{array}$ & mpb \\
\hline * Gerson Bientinez & "Fato" & mpb \\
\hline Gipsy Dream & "Quinze" & mpb \\
\hline * Harqueduque & - & rock \\
\hline * Los bonecos & "Não, espere mais" & rock \\
\hline * Luciano Rosa & "Los Bonecos" & mpb \\
\hline Metralhas & "Lugar ao Sol" & mpb \\
\hline *Mister Jack & "Metralhas Beatles Again" & rock \\
\hline * Musas Curitibanas & "Blues" & blues \\
\hline *Nymphas & "Musas Curitibanas" & mpb \\
\hline $\begin{array}{l}\text { Pain cult, Slack Nipples, Pri- } \\
\text { mal, Abaixo de Deus, Aci- } \\
\text { dose e Convulsão }\end{array}$ & "Pissed Off"(coletânea) & mpb \\
\hline Uv Ray & & rock \\
\hline Via Ápia & "UV Ray" & \\
\hline
\end{tabular}

* CDs já lançados

Os estilos musicais são variados e revelam o perfil diversificado da cidade. É preciso ainda um certo tempo para se poder de fato averiguar a relevância e a permanência de muitos desses artistas num contexto musical mais amplamente nacional ou mesmo local. 


\section{NÄO DÊ PIPOCA AO TURISTA}

Eu gosto de Curitiba / Eu quero ir fundo / No meio do mundo / Aqui é o lugar (refrão)

Olhar as meninas / da praça Osório / pela janela / do meu escritório / Pegar meu salário / dançar no Operário / na Riachuelo / comprar mais um selo / pra te mandar um postal

Passar pela praça / do homem pelado / o Passeio Público / fica ali do lado / De onde se vê as coisas / mais claras / dando pipoca às capivaras

A noite é fria / mas coração é quente / eu quero ir fundo / eu quero ver gente / Tomar um chopinho / na Praça Tiradentes / deixar pendurado na mão do gerente

É madrugada / a noite acabou / nos buracos do Metrô

Harmônica e melodicamente, a canção é bastante simples. Com uma levada que tem tudo para lembrar um jingle feito sob encomenda para comemorar oficialmente o aniversário da cidade, ela vai tirar da tensão que se estabelece entre a letra, o modo de cantá-la e este seu caráter musical os seus efeitos mais expressivos.

A começar pelo primeiro verso, que é também o primeiro verso do refrão, e que portanto se repete algumas vezes ao longo de toda a canção. Da maneira como se encontra estruturada aí a divisão da melodia, tem-se um primeiro segmento em que se canta "Eu gosto de Cu", seguido de uma pequena suspensão provocada por uma estratégica pausa, e que é então finalmente arrematado com as silabas seguintes do nome da cidade - "-ritiba". O efeito é de puro deboche, e corrói de imediato o caráter mais ingenuamente celebratório que poderia estar se insinuando. Os versos seguintes - "Eu quero ir fundo / No meio do mundo / Aqui é o lugar" - acabam por abrigar igualmente um duplo sentido uma vez lidos contra o pano de fundo estabelecido pela divisão musical do primeiro. Para além do enfoque narcisico da cidade enquanto centro umbilical em que se está, ecoam sentidos bastante mais obscenos aí.

Esse caráter de duplicidade percebido no refrão vai permear toda a composição. Toda ela vai oscilar entre a homenagem e a derrisão.

O que poderia ser um puro comprazimento provinciano com a arrolagem de topônimos urbanos locais (e não que de fato não seja assim em certa medida)

9 In: CAREQA. Carlos. Os homens são todos iguais. São Paulo: Camerati. 1993. 
vai se temperando com a notação humorística dos sentidos e dos efeitos sonoros das rimas obtidas: "Olhar as meninas da praça Osório" / "pela janela do meu escritório"; "Pegar meu salário" / "dançar no Operário"; "na Riachuelo" / "comprar mais um selo"; "Tomar um chopinho na praça Tiradentes" / "deixar pendurado na mão do gerente"; "a noite acabou" / "nos buracos do Metrô".

Repare-se que o roteiro proposto pela canção não privilegia necessariamente os locais turisticos mais tipicos - aqueles que costumam povoar justamente os cartões postais e a propaganda oficial. Aliás, desde o título - "Não dê pipoca ao turista" - , o que se insinua é claramente um recorte extra-oficial da cidade. Se há referência ao Passeio Público, por exemplo, ela se encontra meio minada pelo humor da ação ali localizada: "dar pipoca às capivaras". Mas a maior parte dos lugares citados e das ações neles praticadas resvalam pelo marginal. O "Operário" é clube habitualmente freqüentado pelas classes populares e abriga durante o carnaval um tradiconal baile de travestis. A "Riachuelo" é rua meio lendária no imaginário da cidade, conhecida zona de prostituição. Os "buracos do Metrô", do verso final, ao contrário do que ao ouvinte desavisado poderia parecer, remetem à casa noturna "Metrô", outro ponto de prostituição.

Ainda na linha dos efeitos de humor, certas singularidades da pronúncia local são caricaturadas. Assim, toda a seqüência de rimas "quente" / "gente" / "Tiradentes" / "gerente" é pronunciada de forma carregada, com as nasais da penúltima silaba e os /ê/ finais bem marcados. Um traço óbvio da fala local, sempre notado com certo desdém por quem vem de fora.

A música popular brasileira é fértil em homenagens de seus artistas à sua cidade de origem ou a locais que despertaram de algum modo a sua sensibilidade. Quanto já não se cantou a Bahia e o Rio de Janeiro, as praias de Ipanema e Itapoã, o Pelourinho e o Cristo Redentor, para ficar oscilando somente entre dois dos seus centros de excelência. $O$ artista curitibano se inclina à tradição, mas não o deixa de fazer sem a consciência do descompasso. E é aí que se instaura a necessária ironia.

Uma segunda canção é "Passantes", do compositor Luiz Antônio Fidalgo, interpretada pelo grupo Fato, no seu CD homônimo Fato, lançado em 1995.

\section{PASSANTES}

Nessa vitrine ao lado / Estamos nós / Entre a moda e os manequins / Estamos sós / Os brilhos de neon da galeria / Dançam no olhar do guardião / Que fecha a porta e chora / A Schaffer tá fechada / Madrugada adentro e afora 
A chuva sobre a Rua XV cai / Oh! guarda-chuva abracadabra sobre nós / Feche sobre nós as sulas asas / Pretas de guardachuva / Deixe a gente se molhar / Deixe a gente andar cada um na chuva

Sou amigo da menina / Olha eu sou apenas um pobre rapaz / Sou capaz de ser um doce abrigo / Cada amigo é um amante / Na certa sou viajandante / A avenidavida é sempre curta / E essa rua é linda sob a chuva ${ }^{10}$

Em "Passantes", as referências mais explícitas a Curitiba vão funcionar mais como uma espécie de moldura para a cena principal. A "Schaffer" (a Galeria Schaffer) e a "Rua XV", espaços característicos do centro e da alma da cidade, compõem um cenário para o pequeno quadro dos dois namorados. Não há aqui o humor e o deboche da primeira canção, nem uma fixação exclusiva nos lugares pelos lugares. O espaço tem uma outra qualidade, é apreendido de forma bem mais delicada e sutil, adquirindo ao final da canção todo um sentido metafórico e abrangente. Passa-se bem ao largo de uma captação restritamente pitoresca da cidade.

Toda a primeira parte da canção é cantada de forma lenta, sobre um pano de fundo musical cheio de efeitos de som e acordes sustentados, e que abre mão de uma marcação rítmica muito precisa. Na passagem da primeira para a segunda parte, o ritmo toma um perfil mais definido, adquirindo os contornos de uma espécie de baião estilizado que vai se estender até o final.

Em sintonia com o modo como vai se encaminhando a música, a primeira parte da letra vai ter um caráter quase melancólico. Um sujeito que se apresenta aí como um "nós" - e que, nos desdobramentos da canção, explicita-se como um provável casal - percebe-se em seu isolamento em meio ao espaço noturno da cidade. A galeria, possível abrigo, está sendo fechada pelo guardião, que chora.

Na segunda parte, dá-se a transformação. Se há alguma continuidade entre o choro do guardião e a chuva que começa a cair, o que se percebe agora é na verdade um deslocamento em relação ao quadro inicial. A música adensa-se ritmicamente, torna-se dança. E todo o quadro acompanha o clima da música. A chuva que cai sobre a Rua XV é recebida de modo mágico e festivo, como ecoa aliás o belo verso "Oh! guarda-chuva abracadabra sobre nós". Ao invés do desejo de abrigo, o que se quer é ir para o meio da rua - "Deixe a gente se molhar / Deixe a gente andar cada um na chuva".

10 In: FATO. Falo. Curitiba: Produção Independente. 1995. 
E vai ser ainda dentro de um mesmo ambiente festivo que o "nós" das partes anteriores se desvela agora na terceira. Temos diante dos olhos um "rapaz" e uma "menina", um casal cuja relação logo se explicita. O "rapaz" - um "pobre rapaz" - diz-se "amigo da menina", e como tal "um doce abrigo", e ainda como "amigo" também um "amante". $O$ espaço adquire um novo sentido. A rua desdobra-se numa figurada "avenidavida" sobre a qual o "rapaz" se vê na condição de um "viajandante". Mas a rua é ainda também a Rua XV - "E essa rua é linda sob a chuva". Se a vida - a "avenidavida" - é percebida como "sempre curta", a fruição da beleza da "rua sob a chuva", que vai se dar justamente no meio da rua e também sob a chuva-no cerne da própria vida, se poderia dizer -, adquire um caráter compensatório de afirmativo entusiasmo.

A Rua XV surge transformada em espaço de encantamento e afirmação. Metáfora do próprio curso da existência, metáfora do deleite festivo com a beleza e a alegria dessa existência.

A terceira canção, intitulada "Filhos de Gdanski" , é de autoria do compositor carioca Antônio Saraiva e foi gravada pelo grupo curitibano Beijo AA Força no CD Sem suingue, seu segundo trabalho em estúdio. Antônio Saraiva, além de participar dos arranjos e como saxofonista, assina ainda a produção musical do disco. É dele também a produção musical do disco do grupo Fato, que gravou igualmente composições suas.

\section{FILHOS DE GDANSKI}

U/m afoxé muito branco emerge das brumas / o vento frio e a chuva parecem não crer / nos ursos polares. vampiros. destaques do bloco / que varre e suja a cidade de vodka e som

lelhos cristãos já sabiam fazer uma farra / faltava era só aprender a bater agogô / dentro e fora do tempo suingue quadrado / quadris emperrados começam a estremecer

Será que Wojciela de branco encara Oxalä? / Serique oprefeito perfeito vai patentear? / Será que no ano que vem também vão desfilar? / Parece, disseram. que isso veio pra ficar

Loucos e lúcidos dançam nas ruas e parques / sempre cantando en puro polaco-nagô / Agora que já misturaram dendê e Descartes / Gdanski, Curita e Bahia são da mesma cor ${ }^{11}$

11 In: BEIJO AA FORÇA. Sem suingue. Curitiba: Produçăo Independente. 1995. 
"Filhos de Gdanski" é provavelmente a tentativa mais arrojada de apreender o perfil cultural da cidade e o momento musical atual por ela vivido. Curiosamente, é a partir de um olhar de fora que Curitiba vai ser agora entrevista (posto que o olhar seja de alguém que participou nos últimos anos de diferentes projetos artísticos na cidade). O viés "estrangeiro" tem sempre a virtude de revelar o que para o enfoque "nativo" nem sempre pode ser plenamente percebido.

A canção parte da combinação de elementos a princípio muito distintos. A começar pelo título, "Filhos de Gdanski", um trocadilho com o nome do tradicional bloco baiano "Filhos de Gandhi" e a cidade portuária de "Gdanski" (em geral grafada Gdánsk), atualmente em território polonês, mas sob domínio alemão (Danzig) anteriormente à Primeira Guerra. "Gdanski" funciona no texto como uma alusão à imigração eslava (mas também à germânica) que marca a cidade. "Filhos de Gdanski" seriam assim os próprios curitibanos. Também o estilo musical da canção - um afoxé (bastante estilizado no arranjo e execução) - estabelece tensão, pela sua origem afro-baiana, com o tema cantado - a cidade de Curitiba, cidade de perfil étnico e espiritual como que antagônico em relação à Bahia.

Todo o texto se constrói como uma grande alegoria, apoiada num motivo básico: o desfile de carnaval. Um desfile algo fantástico, diga-se, como uma aparição, animado por "um afoxé muito branco que emerge das brumas", em pleno frio e chuva característicos da cidade, com "ursos polares" e "vampiros" como destaques, e sujando tudo, à sua passagem, de "vodka e som". A "farra" que se instala sempre esteve presente na alma "de velhos cristãos" e, para se tornar um carnaval verdadeiro (no sentido forte e brasileiro do termo), "faltava era só aprender a bater agogô". Meio "dentro", meio "fora do tempo", "quadris emperrados começam a estremecer".

Traça-se com essas imagens o perfil de uma cidade em possivel mutação. Curitiba, com a frieza e rigidez que marcam a sua alma (fato/estereótipo tantas vezes repisado), parece querer aderir, à sua maneira, ao carnaval. E o carnaval aqui é a alegria da festa, da dança, da música, os dados de uma brasilidade mais explicita e expressiva que parecia nos faltar. E não é à toa que a Bahia, um dos mais felizes protótipos dessa brasilidade, está semeada em seus diferentes elementos ao longo de toda a composição. Redescobre-se ai a "raiz", o "húmus popular", de que falava Paulo Leminski.

No meio da canção, algumas indagações perpassadas de ironia são levantadas. $E$ os representantes dos poderes religioso e civil vêm à baila. João Paulo II - "Woyciela" no texto - (e o lado católico e eslavo da cidade com ele) é concitado a "encarar" Oxalá, a divindade afro-brasileira. O "prefeito perfeito" (alusão irônica ao propalado sucesso das administrações municipais da cidade), 
a "patentear" o evento. Ambos, ainda, a desfilar no próximo ano. E a constatação final desse trecho abre espaço para a consolidação das mudanças: "Parece, disseram, que isso veio pra ficar".

Todo o segmento final da letra dá continuidade ao jogo de combinaçð̃es desenvolvido: "loucos" / "lúcidos"; "polaco" / "nagô" (na verdade fundidos na expressão "polaco-nagô") ; "dendê" / "Descartes" . Abreviadamente, estão ai lado a lado a loucura (a dança, a música, a embriaguez, a festa) e a lucidez (a reserva, o controle, o comedimento); a mistura dos referencias afro-brasileiros (o "dendê", que é dado da natureza nativa brasileira e ingrediente básico da culinária negra baiana) e europeus ("Descartes", filósofo matriz do intelectualismo racionalista branco ocidental); e ainda o sincretismo alegórico de uma língua imaginária - o "polaco-nagô", língua franca dessa nova festa.

$O$ verso final celebra a mistura e a equivalência das forças - "Gdanski, Curita e Bahia são da mesma cor". Ainda muito mais no plano do desejo do que no da plena realidade, traça-se assim talvez um projeto cultural para a cidade a inevitável e dificil assunção dos elementos locais mesclada à abertura para os dados de fertilização que vêm de fora.

E aqui se pode estrategicamente retomar o incicio deste artigo, voltar ao ponto de partida, justamente à figura emblemática de Paulo Leminski, já que todas as expressões do final da letra da canção de Antônio Saraiva são também alusões explícitas a ele - ao seu celebrado Catatau, ao seu dificil trânsito entre os pólos extremos da lucidez e da loucura, à maneira como ele se referia à sua própria origem familiar - "mestiço de polaca com negro". 12

E à questão levantada no final de um de seus citados ensaios - "Sem raizes e sem carências, que fazer?" 13 -, acreditar que se esteja já aos poucos tentando responder.

\section{RESUMO}

O presente artigo aborda a recente produção de música popular na cidade de Curitiba. Constata a efervescente cena musical local e analisa ainda o texto de très novas canções que têm como tema a própria cidade.

Palavras-chave: 1. Muisica Popular Brasileira. 2. Muisica ('uritibana. 3. Cultura em Curitiba. 4. Canção Popular. 5. Literatura e Canção.

12 A expressão aparece, nas notas sobre o autor, em diversas das obras de Paulo Leminski editadas pela Brasiliense. Cf. p.ex. LEMINSKI. Distraidos venceremos. Sào Paulo: Brasiliense. 1987. p. 135.

13 LEMINSKI. Anseios cripticos. p. 115 


\section{ABSTRACT}

This article evaluates present popular music production in Curitiba. It recognizes its richness and analyses the lyrics of three new songs that are focused on the town.

\section{REFERÊNCIAS BIBLIOGRÁFICAS}

BROWNE, Rodrigo; SMITH, Abonico R. "Made in Paraná". In: Gazeta do Povo. Caderno "Cultura G". 28/02/96

"Folha viva Curitiba". Suplemento semanal da Folha de Londrina para Curitiba. 18/08/95.

LEMINSKI, Paulo."Sem sexo, neca de criação" e "Culturitiba". In: Anseios cripticos. Curitiba: Criar, 1986.

\section{REFERÊNCIAS DISCOGRÁFICAS}

BEIJO AA FORÇA. Sem suingue. Curitiba: Produção Independente. 1995.

CAREQA. Carlos. Os homens são todos iguais. São Paulo: Camerati. 1993. (relançado em CD pela Velas em 1996).

FATO. Fato. Curitiba: Produçào Independente. 1995. 